\title{
A search model of costly product returns *
}

\author{
Vaiva Petrikaitè \\ 2017 May
}

\begin{abstract}
This paper analyses a market in which consumers buy horizontally differentiated products without knowing their exact valuations. By paying return costs, the consumers may return less-preferred items and obtain refunds. The consumers shop sequentially and their shopping strategy is similar to the search strategy of a consumer in a sequential costly search model. Thus, the pricing strategies of firms are identical to those in a price-directed sequential search model. Price competition is more intense, and the symmetric equilibrium price is lower when returns are costlier. As a result, consumer surplus is increasing in the return cost.
\end{abstract}

Keywords: Return cost, horizontal differentiation, duopoly

JEL classification: D43, D83, L13

${ }^{*}$ I am very grateful to the editor and two referees for their constructive comments and suggestions. Additionally, I am obliged to José Luis Moraga-González, Sjaak Hurkens, Jordi Brandts, Matthew Ellman, Ramon Caminal, Roberto Burguet, Chris Wilson, Mikhail Drugov, Egle Karmazienè, the participants of EARIE 2015, the SaM workshop 2015 in Bristol, and the $4^{\text {th }}$ Annual Lithuanian Conference on Economics Research for their invaluable advice and opinions. The title of an earlier version of this paper was "Price Competition with Costly Product Returns". The author acknowledges the financial support of the Ministry of Economy and Competitiveness of Spain Grants No. ECO201459959-P and No. ECO2015-74328-JIN (AEI/FEDER/UE) and BBVA Fundación.

${ }^{\dagger}$ Instituto de Análisis Económico (CSIC) and Barcelona GSE, Campus UAB, 08193 Bellaterra, Barcelona, Spain. E-mail: asvaiva@gmail.com 


\section{Introduction}

Online retail surpasses traditional bricks-and-mortar shopping because of unrestricted shopping time, savings on travel costs and an often greater variety of products. Unfortunately, regardless of high definition pictures, detailed product descriptions and extensive user reviews, while shopping online '[a] consumer is not able to see the goods before concluding the contract' (Directive 2011/83/EU). Thus, consumers are never entirely sure about their valuations of the products that they have bought.1 1 To counteract this issue and make online shopping more attractive, online retailers provide a return option that reduces the problem of imperfect information, and is used quite extensively..$^{2}$ However, the return of unsatisfactory products is often costly for a consumer, and this affects the behaviour of buyers and sellers.

This paper studies how return costs affect price competition and welfare in markets with horizontally differentiated products. In particular, I use a duopoly setting similar to a price-directed search model such as employed by Shen (2015), Choi, Dai, and Kim (2016), and Haan et al. (2017). In the model, consumers observe the prices and some characteristics of the products, and the rest of the products' features can be observed only after buying them. A consumer shops sequentially by buying one product first. If the observed utility of the product is very low, the customer buys the second product. After the second purchase, the consumer picks one product that is more appealing and returns the other one by paying a return cost. If returns become costlier, less consumers acquire both products, thus is becomes more important for a firm to be the first on the shopping list of a consumer. This concern strengthens incentives to reduce prices. Therefore, the symmetric equilibrium price is decreasing in the return cost, which has a positive effect on consumer surplus.

The obtained result suggests that the attempts of policy makers to strike 'the right balance between a high level of consumer protection and the competitiveness of enterprises 3 by making product returns easier for consumers, may have a two-fold effect and may not achieve the desired objective. Specifically, cheaper returns let a consumer try more products and improve matching. However at the same time, price competition becomes softer, which harms consumers.4

In extensions to the main model, I examine how the equilibrium price changes if firms incur costs to handle product returns, if consumers face time restrictions that make them return one product before buying another one, and what return costs firms would choose if they were allowed to. The results show that price competition becomes more intense when consumers have less time to claim for refunds. This happens because the probability to pay the return cost twice makes trying both products less appealing. Hence, the importance to attract first purchases increases, which pushes

\footnotetext{
${ }^{1}$ According to $\mathrm{PWC}(2015)$, about one-fourth of consumers bought electronic devices in-store in 2014 because they preferred to see actual products before buying.

${ }^{2}$ On average, between 25 to 30 per cent of e-orders are returned in the UK (Dave, 2015), and the share of returned orders in the clothing industry in Germany equals 70 per cent (Ram, 2016).

${ }^{3}$ The European Commission: http://ec.europa.eu/consumers/consumer_rights/rights-contracts/directive/index_ en.htm. The website was accessed in February, 2017.

${ }^{4} \mathrm{~A}$ similar effect might be expected after removing hindrances to cross-border e-commerce and increasing the efficiency of cross-border delivery services.
} 
the symmetric equilibrium price down.

The costs to handle product returns reduce profits, and firms put efforts into reducing the number of returns. Fewer returns can be achieved either by lowering prices, which increases the net utility of a product and makes the good more attractive, or by raising the price, which leads to fewer purchases and hence fewer returns. The firms follow the first strategy if the return cost is small. The second strategy is used under high return costs.

A prominent position leads to higher profits in a sequential search market (see e.g. Armstrong, Vickers, and Zhou (2009)). As a result, if allowed, firms prefer to reduce their search costs, and a symmetric equilibrium with positive search costs does not exist. On the contrary in this paper, firms do not have incentives to set zero return costs. The difference arises because the return cost of a firm affects its demand by consumers who have already purchased its product, whereas the search cost of a seller does not have any effect on its demand after a consumer has searched its product.

The sequential shopping strategy of consumers in the present paper resembles the sequential search strategy employed by consumers in markets with search costs and observable prices. As a result, the analysis results are comparable in both settings. In particular, Haan et al. (2017), Choi et al. (2016) and Armstrong and Zhou (2011) show that the symmetric equilibrium price is decreasing in search costs, $5_{5}^{5}$ which is similar to the results in the present paper. The incentives to lower prices intensify in search costs because consumers inspect less products on average, which raises the importance to be searched earlier. Nevertheless, the effect of search costs and return costs on welfare measures are not identical. To be precise, consumer surplus is always increasing in return costs whereas it is often non-monotonic in search costs. The difference arises because no consumer pays a return cost after terminating shopping with the first product, and all consumers pay for the first search. Because of this circumstance, the total paid return costs are non-monotonic in the return cost, whereas the total paid search costs are increasing in the search cost.

On more parallel between the literature on costly consumer search and this paper emerges while comparing the setting with time restrictions on returns with the sequential costly search model with costly recall of Janssen and Parakhonyak (2014). The closeness arises because in both settings, consumers behave alike while deciding whether to continue buying (searching). Janssen and Parakhonyak (2014) show that the introduction of sufficiently high recall costs often has a similar effect on price competition as raising search costs in a sequential search market with costless recall. Similarly, the symmetric equilibrium price is lower if a consumer must return one product before buying another one.

From the economics literature on costly product returns, the work of Shulman et al. (2011) is the closest to this paper. Specifically, they study firms' choices of prices and refund fees when consumers are imperfectly informed about horizontally differentiated products and may return purchased items. The major distinction between this paper and that of Shulman et al. (2011) lies in information

\footnotetext{
${ }^{5} \operatorname{In}$ Armstrong and Zhou (2011), firms mix over an interval of prices, and the expected price is decreasing in search costs.
} 
acquisition. Namely in the present paper, a consumer does not become better informed about a competing product after the first purchase, whereas in Shulman et al. (2011), consumers are distributed around a Salop circle with respect to the unobservable product characteristics and they learn about competing products after the first purchase. Because of this additional detail, Shulman et al. (2011) find that a symmetric equilibrium price is higher when consumers are less informed, and the present study obtains the opposite result. 6

Inderst and Tirosh (2015) study a duopoly market in which two products differ in quality. They find that sellers do not implement a free refund policy, and lower-quality firms offer worse refund conditions to consumers than high-quality firms. Moorthy and Srinivasan (1995) show that highquality sellers use money back guarantees to signal their quality if consumers pay positive transaction costs. In contrast, this paper does not consider any vertical product differentiation and the return policy in not a choice made by firms.

The result that no returns lead to lower prices has also been obtained by other studies. Inderst and Ottaviani (2013) find that a monopolist charges a higher price in equilibrium if the firm's returns policy is more generous..$^{7}$ In their model, a consumer may obtain just a part of the paid price back, which is equivalent to paying a positive return cost. Correspondingly, Che (1996) shows that a monopolist charges a higher price if consumers can use a free return option. Furthermore, Anderson and Hansen (2009) demonstrate that a multiproduct monopolist sets higher prices for its products when consumers can return them..$^{8}$ Unlike those papers, this paper analyses a duopoly market, and the return cost ranges from zero to some positive value. The first aspect of the analysis allows for the consideration of price competition, and the second one permits studying the effect of costly returns.

The rest of this paper is organised as follows. The main modelling assumptions are listed in the subsequent section. They are followed by the analysis in Sections 3 and 4 . There are several extensions in Section 5. Some discussion that concerns future research on the subject can be found in Section 6. The proofs of the propositions and lemmas are relegated to Appendix and Online Appendix.

\section{Set-up}

The demand side of the market consists of a continuum of consumers that I normalise to one. There are two single-product firms on the supply side, each of which offers a horizontally differentiated product. The constant unit production cost is the same for both firms and I normalise it to

\footnotetext{
${ }^{6}$ The result that a returns policy leads to lower profits of firms was also obtained by Krähmer and Strausz (2015), Arya and Mittendorf (2004) and Courty and Li (2000). In those models, an easier option to return a product (or withdraw a contract) hinders the screening of consumers, which leads to less profits.

${ }^{7}$ A similar result has been obtained by Lutz and Padmanabhan (1998) who study the incentives of the monopolist to offer product warranties.

${ }^{8}$ Additionally, Palfrey and Romer (1983) demonstrated that an equilibrium price is decreasing in the travelling costs that a consumer has to pay to buy from a monopolist and to claim for a refund in case the product is faulty; Davis et al. (1995) show that a monopolist earns more by offering money back guarantees when consumers pay return costs.
} 
zero. Firms incur zero costs in handling product returns..$^{9}$

Consumers have unit demand and differ in their tastes for a product. The match between the preferences of consumer $l$ and the features of product $j$ is measured by the sum of two match values $\varepsilon_{l j}+\eta_{l j}$. The variables $\varepsilon$ and $\eta$ are distributed independently and identically across consumers and products according to a uniform distribution on the interval $[0,1]$. The precise values of $\varepsilon$ and $\eta$ are the private information of a consumer. However, the distribution of the match values is common knowledge. There are no negotiations concerning price reduction after a consumer claims a refund. Thus, the seller charges the same price to all its customers. This assumption is realistic in markets where profit margins are low and the turnover is relatively high (e.g. fast fashion, books), which makes personal negotiation very costly. Hence, if consumer $l$ buys product $j$ at price $p_{j}$, then the net surplus (utility) equals

$$
u_{l j}=\varepsilon_{l j}+\eta_{l j}-p_{j}
$$

A consumer wants to buy the product that yields the highest utility. The consumer observes only a part of the total match value, $\eta$, and the price of the product before purchasing, and learns the value of $\varepsilon$ only after paying for the product. Additionally, a firm is obliged to pay money back to the consumer if the consumer does not, after all, like the product. However, the consumer must pay a fixed return cost $r$ in order to receive a refund. This includes the costs that are related to posting the package and waiting for the refund. The return cost is fixed exogenously, is the same for all consumers and both firms, and is observable to everyone.

A consumer is not restricted in time regarding returns, i.e. the consumer may return a product either before buying a subsequent item or in the end of shopping. Therefore, the consumer shops sequentially; buys one product first and makes the second purchase only if the utility of first item has been not high enough. After the second purchase the consumer returns one good and pays the return cost. This shopping strategy is better than buying both products immediately and returning one of them later because there is a positive probability that the product purchased first is better than the second one. Thus, there are expected savings on return costs. I study what happens if consumers must return one item before buying the second one due to time constraints in Section 5.3 .

The utility of an outside option is sufficiently low, so that a consumer always buys one of the two products. Thus, the market is fully covered. Additionally, the return cost $r$ is relatively small and (or) the disutility of keeping an unwanted product is relatively high, so that a consumer prefers paying $r$ to keeping an unused product. The latter assumption is not restrictive because the symmetric equilibrium price is higher than the return cost, which makes returning more appealing. To ensure that some consumers buy both products, I assume that $r \leq 1 / 8$.

This is a two-stage market model. In the first stage, firms simultaneously choose their prices.

\footnotetext{
${ }^{9}$ The main model abstracts from the costs that firms incur to dispose of some products, which may happen due to overproduction, or because consumers damage goods and these items cannot be resold. In those instances, sellers care not only about produced and successfully sold products, but also about the returned items. I check the effect of production costs and the costs of handling product returns in Section 5.1 .
} 
In the second stage, consumers observe the prices and make their decisions about purchases and returns.

\section{Optimal shopping}

In this section, I derive the optimal shopping rule of consumers and show its connection to sequential search models. Suppose that a consumer buys product $i$ first, inspects $\varepsilon_{i}$ and considers buying product $j$. If the consumer buys product $j$, then the consumer returns product $j \neq i$ when $\varepsilon_{i}+\eta_{i}-p_{i} \geq \varepsilon_{j}+\eta_{j}-p_{j}$, and returns product $i$ when the inequality is reversed. As a result, the expected utility gain from buying product $j$ equals

$$
\int_{\varepsilon_{i}+\eta_{i}-p_{i}-\eta_{j}+p_{j}}^{1}\left(\varepsilon_{j}+\eta_{j}-p_{j}-\left(\varepsilon_{i}+\eta_{i}-p_{i}\right)\right) d \varepsilon_{j} .
$$

The consumer is indifferent towards keeping product $i$ and buying product $j$ if (1) equals $r$. Further, I denote the value of $\varepsilon_{i}+\eta_{i}-p_{i}-\eta_{j}+p_{j}$ that makes (1) equal to $r$ by $x$, which is $1-\sqrt{2 r}$. Then, if a consumer observes that $\varepsilon_{i}+\eta_{i}-p_{i}<x+\eta_{j}-p_{j}$, the customer buys product $j$. Otherwise, the customer terminates shopping and keeps product $i$. Similarly, one can derive the utility threshold $x+\eta_{j}-p_{j}$ that the consumer uses to decide whether to buy product $i$ after buying product $j$ first. The described shopping strategy of the consumer resembles the sequential search and stopping rules derived by Weitzman (1979). As a result, I obtain that

Lemma 1 (Weitzman (1979)). An optimally shopping consumer buys product $i$ first if $\eta_{i}-p_{i}>$ $\eta_{j}-p_{j}$, and later, if $\varepsilon_{i}+\eta_{i}-p_{i}<x+\eta_{j}-p_{j}$, buys product $j$. After buying both products the consumer returns the item providing a lower net utility.

Although a consumer buys a product without knowing the actual utility, the possibility to return an inferior item makes the setting similar to the sequential search setting with costless recall. 10 This correspondence arises because the return cost is paid if the consumer decides to learn the utilities of both products. As a result, the return cost can be viewed as the search cost of the second alternative.

\section{Equilibrium}

In this section, I derive the symmetric equilibrium price $p^{*}$. The followed approach is similar to the one of Haan et al. (2017). Alternatively, one could apply the discrete choice modelling, as in Armstrong and Vickers (2015), Armstrong (2016) and Choi et al. (2016), which I use to prove the existence of a symmetric equilibrium in the proof of Proposition 1 .

\footnotetext{
${ }^{10}$ This is in contrast to the analysis of Doval $(2016)$, Fishman and Lubensky $(2016 \mathrm{a})$ and Gamp (2016) in which a consumer keeps a purchased product even if it provides a lower utility than expected before buying.
} 
To simplify the expressions of the pay-off functions, I define $\Delta_{\eta}=\eta_{j}-\eta_{i}$, and $\Delta_{p}=p_{j}-p_{i}$. Additionally, I use the distribution function of $\Delta_{\eta}$ that is denoted by $\Gamma\left(\Delta_{\eta}\right)$.

$$
\Gamma\left(\Delta_{\eta}\right)=\operatorname{Pr}\left[\eta_{j}-\eta_{i} \leq \Delta_{\eta}\right]= \begin{cases}1-\frac{1}{2}\left(1-\Delta_{\eta}\right)^{2}, & \Delta_{\eta} \geq 0 \\ \frac{1}{2}\left(1+\Delta_{\eta}\right)^{2}, & \Delta_{\eta}<0\end{cases}
$$

The density function of $\Delta_{\eta}, \gamma\left(\Delta_{\eta}\right)$, is symmetric with respect to zero, and log-concave.

Consider firm $i$ that slightly deviates by setting $p_{i} \neq p^{*}$. Firm $j \neq i$ charges $p^{*}$. The demand for product $i$ consists of three parts: the demand by consumers who start shopping at firm $i$ and never consider going to firm $j$, the demand by consumers who start shopping at firm $i$ and later may continue shopping at firm $j$, and the demand by consumers who start shopping at firm $j$ and buy from firm $i$ afterwards.

The demand by the first group is denoted by $q_{0 i}$. These consumers have a significantly large difference between $\eta_{i}$ and $\eta_{j}$, and therefore they do not shop at firm $j$ even if $\varepsilon_{i}=0$. The share of these consumers equals the probability that $\Delta_{\eta} \leq \Delta_{p}-x$. Thus, $q_{0 i}=\Gamma\left(\Delta_{p}-x\right)$.

Now consider a consumer from the second group. The consumer starts shopping at firm $i$ if $\Delta_{\eta} \leq \Delta_{p}$. The consumer buys product $i$ and decides to keep it without purchasing product $j$ if $\varepsilon_{i}+\eta_{i}-p_{i} \geq x+\eta_{j}-p^{*}$. The conditional probability of this event equals $1-\left(x+\Delta_{\eta}-\Delta_{p}\right)$.

If the consumer finds that the utility of product $i$ is below the reservation utility of product $j$, then the consumer buys product $j$ and keeps product $i$ if $\varepsilon_{i}+\eta_{i}-p_{i} \geq \varepsilon_{j}+\eta_{j}-p^{*}$. The conditional probability of this event is

$$
\int_{\max \left\{0, \Delta_{\eta}-\Delta_{p}\right\}}^{x+\Delta_{\eta}-\Delta_{p}}\left(\varepsilon+\Delta_{p}-\Delta_{\eta}\right) d \varepsilon
$$

By adding the two probabilities and integrating over the interval of admissible values of $\Delta_{\eta}$, I obtain the demand for product $i$ by the second group of consumers. This demand is denoted by $q_{1 i}$.

$$
q_{1 i}=\int_{\Delta_{p}-x}^{\Delta_{p}}\left[1-\left(x+\Delta_{\eta}-\Delta_{p}\right)+\int_{0}^{x+\Delta_{\eta}-\Delta_{p}}\left(\varepsilon+\Delta_{p}-\Delta_{\eta}\right) d \varepsilon\right] d \Gamma\left(\Delta_{\eta}\right)
$$

Next, consider a consumer who starts shopping at firm $j$. The consumer has bought product $j$ first because $\Delta_{\eta}>\Delta_{p}$. The consumer buys product $i$ if $\varepsilon_{j}+\eta_{j}-p^{*}<x+\eta_{i}-p_{i}$. If the consumer buys both products and decides to keep product $j$, then the highest utility that can be obtained equals $x+\eta_{i}-p_{i}-r$. Therefore, if $\varepsilon_{i} \geq x$, then the consumer keeps product $i$. Suppose that $\varepsilon_{i}<x$. Then, the consumer keeps product $i$ and returns product $j$ if $\varepsilon_{i}+\eta_{i}-p_{i} \geq \varepsilon_{j}+\eta_{j}-p^{*}$. Thus, conditional on the consumer buying product $j$ first, the probability that the consumer buys and keeps product $i$ equals

$$
\left(x+\Delta_{p}-\Delta_{\eta}\right)(1-x)+\int_{\max \left\{0, \Delta_{\eta}-\Delta_{p}\right\}}^{x}\left(\varepsilon+\Delta_{p}-\Delta_{\eta}\right) d \varepsilon
$$


Now, by integrating over the interval of the relevant values of $\Delta_{\eta}$, I obtain the demand for product $i$ by the consumers who start shopping at firm $j$. This demand is denoted by $q_{2 i}$.

$$
q_{2 i}=\int_{\Delta_{p}}^{x+\Delta_{p}}\left[\left(x+\Delta_{p}-\Delta_{\eta}\right)(1-x)+\int_{\Delta_{\eta}-\Delta_{p}}^{x}\left(\varepsilon+\Delta_{p}-\Delta_{\eta}\right) d \varepsilon\right] d \Gamma\left(\Delta_{\eta}\right)
$$

The pay-off of the seller equals its total revenue:

$$
\pi_{i}=p_{i}\left(q_{0 i}+q_{1 i}+q_{2 i}\right)
$$

In a symmetric equilibrium, firm $i$ sets $p^{*}$. This price is obtained by solving the first-order condition of firm $i$ and is given by (2).

$$
p^{*}=\frac{3}{4 x^{3}-6 x^{2}+6}
$$

Proposition 1. There is a unique symmetric equilibrium in the market, in which both firms charge $p^{*}$. The price $p^{*}$ is decreasing in $r$.

There are two aspects regarding return costs that firms take into account while setting their prices. They are product differentiation and the incentives of consumers to buy two products. If the return cost is small, then more consumers buy both products. Thus, more consumers observe different values of $\varepsilon$, which implies that on average consumers see products more horizontally differentiated. Higher product differentiation equips firms with more market power, which leads to higher prices. An increase in $r$ decreases the number of second purchases, which makes products more similar to an average consumer and strengthens price competition. In addition, the value of $x$ is decreasing in $r$. This implies that consumers buy both products less often. Thus, demand $q_{2 i}$ decreases and it becomes more important for firm $i$ to attract first purchases. The price $p_{i}$ is the only tool that firm $i$ can use to manipulate its demand. Thus, the incentives to set a lower $p_{i}$ increase if $r$ goes up ${ }^{11}$ As a result, the symmetric equilibrium price $p^{*}$ is decreasing in $r$.

In equilibrium, both firms split the market evenly, and the profit of a firm is decreasing in $r$ due to a decreasing $p^{*}$. Meanwhile, to determine how consumer surplus varies with $r$, it is necessary to consider three effects. The first effect is negative: the average ex-post match value of purchased products is lower when $r$ is higher. This happens because more consumers terminate shopping after the first purchase and keep products providing less utility. The second effect is positive: the equilibrium price is decreasing in $r$. The third effect comes via the total paid return costs, and it may be either positive or negative. That is, if the return cost increases, a consumer pays more to return a good. However, at the same time, fewer consumers buy both products, and fewer consumers pay the return cost. As a result, the total paid return costs are non-monotonic in $r$.

\footnotetext{
${ }^{11} \mathrm{~A}$ more detailed discussion on these incentives can be found in Haan et al. (2017).
} 
Proposition 2. Consumer surplus is increasing in $r$ and welfare is decreasing in $r$.

The dominating effect of the return cost on consumer surplus comes via the equilibrium price: products are cheaper when it is costlier to return. Meanwhile, the difference between the total obtained match value and the total paid return costs is decreasing in $r$. As a result, welfare is lower if it is costlier to return products. 12

\section{Model extensions}

\subsection{Positive costs for handling returns}

So far it has been assumed that there are no costs that firms bear to handle returned products. Online retailers have well-developed delivery and return systems that do allow for minimising these costs. Therefore, the assumption about zero costs to handle product returns does not depart greatly from the reality. Unfortunately, the situation is very different during peak retail seasons, such as Christmas time 13 In this section, I analyse how the costs to handle product returns affect the symmetric equilibrium price by introducing a parameter $c$ that measures the cost of handling one returned item. This cost is the same for both firms and does not depend on the volume of the returned items.

Consider the deviation of firm $i$ to $p_{i} \neq p^{*}$. The firm receives its product back from two groups of consumers. The first group are those who start shopping at firm $i$, and later they may shop at firm $j$. The second group of consumers are those who start shopping at firm $j$ and shop at firm $i$ later. A consumer from the first group returns product $i$ if $\varepsilon_{i}<\min \left\{x+\Delta_{\eta}-\Delta_{p}, \varepsilon_{j}+\Delta_{\eta}-\Delta_{p}\right\}$. A consumer from the second group returns product $i$ if $\varepsilon_{i}<\min \left\{x, \varepsilon_{j}+\Delta_{\eta}-\Delta_{p}\right\}$ and $\varepsilon_{j}<x-$ $\Delta_{\eta}+\Delta_{p}$. Thus, the total costs of firm $i$ for handling returns are

$$
\begin{aligned}
C_{i}\left(\Delta_{p}, r\right) & =c \int_{\Delta_{p}-x}^{\Delta_{p}}\left(\int_{0}^{x+\Delta_{\eta}-\Delta_{p}}\left(1-\left(\varepsilon-\Delta_{\eta}+\Delta_{p}\right)\right) d \varepsilon\right) d \Gamma\left(\Delta_{\eta}\right) \\
& +c \int_{\Delta_{p}}^{x+\Delta_{p}}\left(\int_{\Delta_{\eta}-\Delta_{p}}^{x}(x-\varepsilon) d \varepsilon+\left(x-\Delta_{\eta}+\Delta_{p}\right)\left(\Delta_{\eta}-\Delta_{p}\right)\right) d \Gamma\left(\Delta_{\eta}\right) .
\end{aligned}
$$

In this case, the symmetric equilibrium price equals

$$
p^{*}=\frac{3-c x^{2}(4 x-3)}{6-6 x^{2}+4 x^{3}} .
$$

\footnotetext{
${ }^{12}$ In Haan et al. (2017), consumer surplus is non-monotonic in search costs if the interval of the search costs is sufficiently wide. This happens because consumers pay for their first searches in that model, whereas a consumer who terminates shopping after the first purchase does not pay any return costs. To see it, one must subtract $r / 2$ from the expression of consumer surplus that is computed in Appendix. The new expression is non-monotonic in $r$ : it is increasing in $r$ for low values of $r$, but it is decreasing in $r$ if $r$ is high.

${ }^{13}$ According to the Economist (2013), handling a returned item costs $\$ 6-\$ 18$ for a firm.
} 
If $x>3 / 4$, the price is decreasing in $c$. Otherwise $p^{*}$ is higher when it is costlier to handle returned products. ${ }^{14}{ }^{15}$

Proposition 3. Suppose that both firms incur a positive cost c per returned unit. Then, $p^{*}$ is decreasing in $c$ if $x>3 / 4$, and is increasing in $c$ if $x<3 / 4$.

A firm may decrease the volume of returns in two ways: by lowering the price to such a degree that prevents returning, or by raising the price to such a degree that decreases the volume of purchases and returns at the same time. When the return cost is small, the first choice is more appealing. As a result, price competition becomes more intense when $c$ increases, and $p^{*}$ is decreasing in $c$. On the contrary, if the return cost is high, sellers prefer to raise their prices to decrease the volume of returns via fewer purchases. Thus, the symmetric equilibrium price is increasing in $c$ when the returns are very costly: ${ }^{16}$

\subsection{Choosing a return cost}

Although many online sellers allow product returns, return costs may differ across firms. For instance, Palladium states that they deduct 7.5 EUR from every return from EU countries 17 . A consumer who bought a book from Barnes and Noble online complained that she had to put extra effort into returning the item because the traditional shops of Barnes and Noble refused to take the book.18 Meanwhile, Mango allows consumers to choose whether they want to return online purchased products by post or bring them to stores for free. In this section, I provide arguments showing that, even if the return costs are not an addition to revenue, firms never set their return costs equal to zero in a symmetric equilibrium. The detailed derivations of demands and the proof of Proposition 4 are in the online appendix to the present paper.

When the return costs of both sellers are identical, the difference between the reservation utilities of the two products depends on the differences between their observable characteristics and prices (see Section 3). Under different return costs, the products have different values of $x$. In particular, the reservation utility of product $i$ equals $x_{i}+\eta_{i}-p_{i}+r_{i}$. Similarly to Lemma 1, a consumer shops sequentially, starts shopping with the product having a higher reservation utility and makes the second purchase if the observed utility is less than the second-highest reservation utility. As a result, the demand for product $i$, when firm $i$ deviates to $p_{i} \neq p^{*}$ and $r_{i} \neq r^{*}$, is very similar to the one derived in Section 4. The only difference is that one must additionally consider the differences $x^{*}-x_{i}$ and $r^{*}-r_{i}$.

\footnotetext{
${ }^{14}$ I checked the pay-off function $\pi_{i}\left(\Delta_{p}\right)=p q_{i}\left(\Delta_{p}\right)-C_{i}\left(\Delta_{p}\right)$ numerically, and found it to be quasi-concave in $p_{i}$.

${ }^{15}$ If $c$ is sufficiently high, then $p^{*}$ and profits are increasing in $r$ when $r$ is sufficiently small.

${ }^{16}$ If there was a positive constant unit production cost $c_{p}$ and products could not be resold, then the pay-off of the firm would be $\left(p_{i}-c_{p}\right) q_{i}-C_{i}\left(\Delta_{p}, r\right)$, where $c_{p}$ is added to $c$. In this instance, $p^{*}$ would be increasing in $c_{p}$ because $\frac{\partial p^{*}}{\partial c_{p}}=1-\frac{x^{2}(4 x-3)}{4 x^{3}-6 x^{2}+6} \geq 0$.

${ }^{17}$ http://www.palladiumboots.com/blog/eu/customer-service/returns/. The website was accessed in March 2016.

${ }^{18}$ The complaint was posted by Suzane on $29^{t h}$ of Feb. 2016 on http://www.returnsandrefunds.com/Barnes\% 20and\%20Noble/Returns. The website was accessed in April, 2016.
} 
Suppose that firms may choose both their return costs and prices, and firm $i$ considers raising its return $\operatorname{cost} r_{i}$ slightly. The seller considers the following effects of this choice on its pay-off. Firstly, a higher return cost discourages consumers from returning product $i$ once it has been bought. In particular, after buying both products $i$ and $j$, product $i$ is kept if $\varepsilon_{i}+\eta_{i}-p_{i}-r_{j}>\varepsilon_{j}+\eta_{j}-p_{j}-r_{i}$. The probability that product $i$ is kept equals $\varepsilon_{i}-\Delta_{\eta}+\Delta_{p}-r_{j}+r_{i}$ and it is increasing in $r_{i}$. Secondly, consumers are rational, and they understand that due to high $r_{i}$ it will be costlier to return product $i$ if $\varepsilon_{i}$ is low. Therefore, fewer consumers start their shopping from firm $i$. To show this, I take the derivative of the reservation utility of product $i$ with respect to $r_{i}$ : the derivative is negative: $1-\left(1-x_{i}\right)^{-1} \leq 0$. As a result, there are more consumers who find the reservation utility of product $j$ higher when $r_{i}$ increases, and more consumers start their shopping with product $j$. Thirdly, because the reservation utility of product $i$ decreases, fewer consumers buy from firm $i$ after shopping at firm $j$. This is the second negative effect on the demand of the firm. If the return cost is initially low, then the positive effect of $r_{i}$ on the pay-off is stronger. Therefore, firm $i$ does not set $r_{i}=0$ in equilibrium. 19

Proposition 4. Suppose that both firms may choose their return costs. Then, there is no symmetric equilibrium in pure strategies in which both sellers set zero return costs.

\subsection{Restrictions on a return period}

In the main model, a consumer is allowed to return a less-preferred product after observing the utilities of both goods. However, it may not be feasible in some markets due to more restrictive return policies or long shipping periods. In particular, the consumer may be obliged to return one item before buying another. To distinguish from the main setting, I call the modified set-up early returns. The detailed analysis of this setting is in the online appendix to this paper, and here I provide a summary of it.

Optimal shopping. If a consumer has to return one product before buying another one, then there is a chance that the return cost is paid twice. This happens if the consumer decides to repurchase the first product. The consumer evaluates the probability of the additional return and may opt for non-sequential shopping. This choice depends on the difference between the observable characteristics and the return cost. Suppose that the return cost is small and $\eta_{i}$ is much greater than $\eta_{j}$. In this instance, the consumer knows that it is quite unlikely that the net utility of product $j$ is higher than that of product $i$. Hence, if the consumer shops sequentially by buying product $i$ first, then the probability of buying product $j$ is low. Thus, there is a high chance of paying no return cost at all. As a result, the consumer opts for sequential shopping. On the contrary, if $\eta_{i}$ and $\eta_{j}$ are close to each other and $r$ is small, then the probability of the second purchase is

\footnotetext{
${ }^{19}$ The fact that firms prefer preventing consumers from keeping competing products at the expense of fewer purchases is similar to the findings of Fishman and Lubensky (2016b). They study ordered sequential search with costly recall and show that a small positive recall cost benefits firms that are further in the search order.
} 
high. Additionally, the probability of paying the return cost twice is high, because the net expected utilities of both products are close. Hence in this instance, the consumer shops non-sequentially, buys both products immediately and returns one of them after observing both es. Finally, if $r$ is sufficiently high, then sequential shopping is optimal irrespective of the difference between $\eta_{j}-\eta_{i}$. This is because a high return cost makes the reservation utilities of the products low, which makes the probability of the second purchase low and the probability of paying no return cost at all high. To summarise, if returns are early, a firm may face two segments of consumers with respect to their shopping strategies: sequential and non-sequential shoppers.

It was shown in Section 3 that the return cost induces a similar consumer behaviour as the search cost in a sequential search model. If returns are early, then a similar principle applies. In particular, the shopping strategy of a sequentially shopping consumer in the market with early returns resembles the search strategy of a consumer in a sequential search model with costly recall as in Janssen and Parakhonyak (2014). The derivation of reservations utilities is alike.

Equilibrium prices. Janssen and Parakhonyak (2014) show that introducing recall costs is often qualitatively equivalent to raising search costs in the sequential search model with costless recall 20 However, it is not always obvious if the symmetric equilibrium price in the market with early returns may be obtained by raising the return cost in the setting of Section 4 . This is because of the two aforementioned segments of consumers. If the return cost is so high that no consumer shops nonsequentially, then the result follows from the fact that search intensity is lower under early returns, which increases price competition and drives the symmetric equilibrium price down. Furthermore, consider such a return cost under which some consumers shop non-sequentially. Then there are two effects on the symmetric equilibrium price. The first effect is pro-competitive: the consumers who shop sequentially buy both products less often than in the main setting, and firms compete for the first purchases more fiercely by reducing their prices. Secondly, the demand elasticity of a non-sequentially shopping consumer is independent of the return cost (though the number of such consumers depends on $r$ ). This is because the consumer knows that the return cost is inevitable and it is a fixed cost for participation in the market. Then the demand by such a consumer resembles the demand by a fully informed consumer, which creates incentives to raise prices. As a result, whether the symmetric equilibrium price under early returns is lower or greater than $p^{*}$ depends on which effect is stronger. The detailed analysis of the case shows that the first effect dominates and the symmetric equilibrium price is lower if returns are early.

Nonetheless, whether consumer surplus is higher or lower under early returns depends on the return cost. When the return cost is small and returns are early, many consumers shop nonsequentially, the two equilibrium prices are very close to each other and consumer surplus is lower. This happens because consumers pay more return costs in total under early returns. However, if the

\footnotetext{
${ }^{20}$ It can be observed by setting search costs equal to recall costs in the expression of a symmetric equilibrium price in the the supplementary material to Janssen and Parakhonyak (2014).
} 
return cost is high, the difference between the equilibrium prices is higher, and this circumstance changes the order of consumer surplus: consumers are better off under early returns. Welfare is lower under early returns because of worse matching.

\section{Discussion}

Because of an increasing importance of the Internet in the total economy ${ }^{21}$ online retail and internet search have attracted the attention of market regulators, businesses and scientists. The present paper provides some insights into online markets with product returns. In particular, the study shows that lower return costs alleviate price competition and decrease consumer surplus; although it is beneficial for welfare. Irrespective of several extensions, the paper has not covered all interesting aspects of online markets that are worth studying in the future. These are related to abusive consumer behaviour regarding returns and optimal return periods.

Wardrobing or renting is one of the biggest challenges currently faced by retailers. The sellers admit that much clothing and many shoes are returned dirty after having been worn and electronic devices are returned after having been used. In these instances, a consumer buys a product, obtains utility from using it and has sufficient time to claim for a refund by returning the item. Firms are tackling this issue by restricting the requirements for returned garments, using safety stickers that have to be removed before clothing is worn, and blocking the accounts of shoppers that buy and return too often. These stricter return policies help to counteract abusive consumer behaviour, however they may scare away some consumers who are considering buying legitimately. As a result firms should consider the following question that deserves the attention of future market studies: "if some purchasers walk away because as a retailer you have made wardrobing much more difficult, were they ever of any real value to you as customers?' (Vista House, 2016).

This paper studies a duopoly model in which a consumer may return one product after buying two goods. The analysis of the markets with more firms introduces one more aspect to consider: the length of the return period. If a sequentially shopping consumer may return unnecessary products after terminating shopping, then the model resembles a sequential search model with costless recall. Thus, the comparative statics result with respect to the number of firms is as in Wolinsky (1986) and Anderson and Renault (1999). However, if there are many sellers, it is quite unnatural to assume that a consumer does not face any time restrictions for returns. In particular, if the total number of firms equals $n$, then the consumer may be obliged to return the first-purchased product not later than after the $k^{t h}, k<n$, purchase. This complicates the derivation of the optimal shopping rule. However, this type of analysis would allow for a more precise evaluation of the effect of economic policy determining the length of the return period.

\footnotetext{
${ }^{21}$ E-commerce took about 3.11 per cent of the global GDP in 2016: https://www.ecommerce-europe.eu/. The website was accessed in March, 2017.
} 


\section{References}

Anderson, E. T. and K. Hansen (2009). The option value of returns: Theory and empirical evidence. Marketing Science 28(3), 405-423.

Anderson, S. P. and R. Renault (1999). Pricing, product diversity, and search cost: a BertrandChamberlin-Diamond model. RAND Journal of Economics 30(4), 719-735.

Armstrong, M. (2016). Ordered consumer search. MPRA Working Paper No. 72194.

Armstrong, M. and J. Vickers (2015). Which demand systems can be generated by discrete choice? Journal of Economic Theory 158, Part A, 293 - 307.

Armstrong, M., J. Vickers, and J. Zhou (2009). Prominence and consumer search. RAND Journal of Economics 40(2), 209-233.

Armstrong, M. and J. Zhou (2011). Paying for prominence. Economic Journal 121(556), 368-395.

Arya, A. and B. Mittendorf (2004). Using return policies to elicit retailer information. RAND Journal of Economics 35(3), 617-630.

Bagnoli, M. and T. Bergstrom (2005). Log-concave probability and its applications. Economic Theory 26(2), 445-469.

Che, Y.-K. (1996). Customer return policies for experience goods. Journal of Industrial Economics $44(1), 17-24$.

Choi, M., Y. Dai, and K. Kim (2016, November). Consumer search and price competition.

Courty, P. and H. Li (2000). Sequential screening. Review of Economic Studies 67(4), 697-717.

Dave, V. (2015, January 21). About face-reversal of fortune. On the website of Supply Demand Chain Exclusive http://www.sdcexec.com/article/12037309/ statistics-reveal-8-to-9-percent-of-goods-purchased-at-stores-get-returned-and-25-to-30-percent-of-e-retail The website was accessed in Apr., 2016.

Davis, S., E. Gerstner, and M. Hagerty (1995). Money back guarantees in retailing: matching products to consumer tastes. Journal of Retailing 71(1), $7-22$.

Doval, L. (2016, December). Whether or not open Pandora's box.

Fishman, A. and D. Lubensky (2016a, October). Learning match quality.

Fishman, A. and D. Lubensky (2016b, October). Search prominence and recall costs.

Gamp, T. (2016). Search, differentiated products and obfuscation. 
Haan, M., J. L. Moraga-González, and V. Petrikaitè (2017, April). A model of directed consumer search.

Inderst, R. and M. Ottaviani (2013). Sales talk, cancellation terms, and the role of consumer protection. Review of Economic Studies 80(3), 1002-1026.

Inderst, R. and G. Tirosh (2015). Refunds and returns in a vertically differentiated industry. International Journal of Industrial Organization 38, 44 - 51.

Janssen, M. and A. Parakhonyak (2014). Consumer search markets with costly revisits. Economic Theory (55), 481-514.

Krähmer, D. and R. Strausz (2015). Optimal sales contracts with withdrawal rights. Review of Economic Studies 82, 762-790.

Lutz, N. A. and V. Padmanabhan (1998). Warranties, extended warranties, and product quality. International Journal of Industrial Organization 16(4), 463 - 493.

Moorthy, S. and K. Srinivasan (1995). Signaling quality with a money-back guarantee: The role of transaction costs. Marketing Science 14(4), 442-466.

Palfrey, T. and T. Romer (1983). Warranties, performance, and the resolution of buyer-seller disputes. Bell Journal of Economics 14(1), 97-117.

PWC (2015, February). Total retail 2015: Retailers and the age of distruption. On the website of PWC http://www.pwc.com/totalretail. The website was accessed in Jan., 2016.

Ram, A. (2016, January 16). UK retailers count the cost of returns. On the website of Financial Times https://www.ft.com/content/52d26de8-c0e6-11e5-846f-79b0e3d20eaf. The website was accessed in Feb., 2016.

Shen, J. (2015, April). Ex-ante preference in a consumer search market.

Shulman, J. D., A. T. Coughlan, and R. C. Savaskan (2011). Managing consumer returns in a competitive environment. Management Science 57(2), 347-362.

the Economist (2013). Return to Santa. The Economist 2013 Dec 21, On the website of the Economist http://www.economist.com/news/business/ 21591874--e--commerce--firms--have--hard--core--costly--impossible--please--customers--return--santa.

The website was accessed in Apr., 2016.

Vista House (2016, July). Stores fight back in the war on 'wardrobing'. On the website The Blog of Vista House http://vistasupport.com/news-and-events/industry-news/2016/ stores-fight-back-in-the-war-on-wardrobing. The website was accessed in Feb., 2017. 
Weitzman, M. L. (1979). Optimal search for the best alternative. Econometrica 47(3), 641-654.

Wolinsky, A. (1986). True monopolistic competition as a result of imperfect information. Quarterly Journal of Economics 101(3), 493-512. 


\section{Appendix}

Proof of proposition 1. The proof of the proposition consist of two parts. In the first part, I prove that the pay-off function of a firm is quasi-concave which ensures the existence of a unique symmetric equilibrium. In the second part, I provide the comparative statics result.

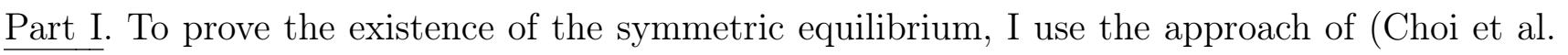
(2016)). In particular I define the variable $w=\eta+\min \{x, \varepsilon\}$, which distribution function is

$$
H(w)= \begin{cases}\int_{0}^{w}(w-\varepsilon) d \varepsilon, & w \leq x, \\ \int_{0}^{x}(w-\varepsilon) d \varepsilon+\int_{x}^{1}(w-x) d \varepsilon, & x<w \leq 1, \\ w-1+\int_{w-1}^{x}(w-\varepsilon) d \varepsilon+\int_{x}^{1}(w-x) d \varepsilon, & w>1 .\end{cases}
$$

The corresponding density function of $w$ and the derivative of the density function are

$$
h(w)=\left\{\begin{array}{ll}
w, & w \leq x, \\
1, & x<w \leq 1, \\
2-w, & w>1 .
\end{array} \quad h^{\prime}(w)= \begin{cases}1, & w \leq x, \\
0, & x<w \leq 1 \\
-1 & w>1 .\end{cases}\right.
$$

Then, the demand by firm $i$ is the probability that $w_{i}-p_{i}>w_{j}-p^{*}$, which gives $q_{i}=$

$\int_{0}^{1+x} H\left(w+\Delta_{p}\right) d H(w)$. The density function $h(w)$ is log-concave. Thus, by following Bagnoli and Bergstrom (2005), I conclude that $H(w)$ is log-concave, which renders the pay-off of the firm quasiconcave.

Part II. To prove that $p^{*}$ is decreasing in $r$, it suffices to show that the denominator in (2) is decreasing in $x$. The derivative of the denominator with respect to $x$ is indeed negative: $12 x^{2}-12 x<$ 0 .

Proof of Proposition 2, The total consumer surplus equals twice the consumer surplus of the consumers who buy from firm $i$. The latter equals

$$
\begin{aligned}
C S_{i} & =\int_{x}^{1} \int_{0}^{\eta_{i}-x}\left(\frac{1}{2}+\eta_{i}\right) d \eta_{j} d \eta_{i}-\frac{1}{2} p^{*} \\
& +\int_{0}^{1} \int_{\max \left\{0, \eta_{i}-x\right\}}^{\eta_{i}}\left(\int_{x+\Delta_{\eta}}^{1}\left(\varepsilon+\eta_{i}\right) d \varepsilon+\int_{0}^{x+\Delta_{\eta}}\left(\varepsilon-\Delta_{\eta}\right)\left(\varepsilon+\eta_{i}-r\right) d \varepsilon\right) d \eta_{j} d \eta_{i} \\
& +\int_{0}^{1} \int_{\eta_{i}}^{\min \left\{1, x+\eta_{i}\right\}}\left(\left(x-\Delta_{\eta}\right) \int_{x}^{1}\left(\varepsilon+\eta_{i}-r\right) d \varepsilon+\int_{\Delta_{\eta}}^{x}\left(\varepsilon-\Delta_{\eta}\right)\left(\varepsilon+\eta_{1}-r\right) d \varepsilon\right) d \eta_{j} d \eta_{i} \\
& =\frac{1}{60}\left(35+15 x^{2}-25 x^{3}+15 x^{4}-3 x^{5}\right)-\frac{1}{2} p^{*}-\frac{x^{2}}{6} r(3-x) .
\end{aligned}
$$


The derivative of the surplus with respect to $x$ is negative

$$
\frac{\partial C S_{i}}{\partial x}=\frac{1}{6} x\left(x^{3}-4 x^{2}+3 x-\frac{27(1-x)}{\left(3+x^{2}(2 x-3)\right)^{2}}\right)<0 .
$$

Hence, the consumer surplus is increasing in $r$.

To compute the effect of $r$ on welfare I add $p^{*} / 2$ to the expression of $C S_{i}$ and take the derivative of the obtained expression with respect to $x$. The derivative is positive: $x^{2}\left(x^{2}-4 x+3\right) / 6 \geq$ $x^{2}\left(1^{2}-4+3\right) / 6=0$, which implies that the welfare is decreasing in $r$. 